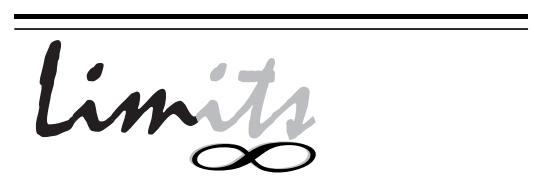

J. Math. and Its Appl.

ISSN : $1829-605 \mathrm{X}$

Vol. 7, No. 2, November 2010, 27-40

\title{
ESTIMASI MODEL EKSPONENSIAL LIFETIME DENGAN DOUBLE CENSORING
}

\author{
Farida Agustini W. ${ }^{1}$, Thathit Purwaningtyas ${ }^{2}$ \\ Jurusan Matematika, FMIPA ITS Surabaya \\ ${ }^{1}$ farida_sahlan@yahoo.com, ${ }^{2}$ thathit@sss_sub.sig.co.id
}

\begin{abstract}
Abstrak
Analisis lifetime merupakan analisis statistik yang memodelkan lama waktu sampai terjadinya suatu kejadian. Penelitian ini menggunakan Distribusi Eksponensial untuk mengestimasi data lifetime dengan double censoring dan menggunakan metode Bayesian yang berdasarkan distribusi prior gamma. Informasi sampel (distribusi prior) tersebut dikombinasikan dengan fungsi likelihood untuk mendapatkan distribusi posterior, sehingga didapatkan estimator dari $\mu$ yaitu $\bar{\mu}$ dan interval kepercayaan $(1-\alpha) 100 \%$ untuk $\mu$, yaitu: $P\left(c_{1} \leq \bar{\mu} \leq c_{2} \mid x\right)=1-\alpha$ dimana penentuan nilai $\left(c_{1}, c_{2}\right)$ didapatkan dengan pendekatan numerik dengan bantuan Matlab 7.0 pada penerapan kasus.
\end{abstract}

Katakunci: Distribusi eksponensial, double censoring, metode bayesian, distribusi posterior

\section{Pendahuluan}

Pengamatan data lifetime berguna dalam melakukan pengujian daya tahan dan keandalan suatu hasil teknologi dan industri. Selain sangat diperlukan dalam peningkatan kualitas suatu produk, analisis terhadap data lifetime 
pada kondisi perlakuan atau operasional tertentu banyak dilakukan oleh para ilmuwan di berbagai bidang ilmu.

Beberapa model distribusi yang sering digunakan dalam pengamatan data lifetime ini yaitu distribusi Weibull, distribusi Gamma, distribusi Eksponensial dan distribusi Lognormal. Pada penelitian ini distribusi yang digunakan adalah distribusi Eksponensial karena distribusi tersebut banyak digunakan dalam analisis uji lifetime. Pengambilan sampel dalam uji lifetime dilakukan secara censoring sehingga waktu pengujian lebih efisien. Terdapat berbagai macam tipe sampel censoring yang bisa digunakan diantaranya sampel single censoring dan double censoring. Sampel double censoring adalah sampel data yang disensor kedua-duanya yaitu right censoring dan left censoring, sedangkan sampel single censoring merupakan tipe censoring yang hanya dilakukan satu kali, yaitu right censoring saja atau left censoring. Penggunaan sampel double censoring lebih menghemat waktu dan tenaga jika dibandingkan dengan sampel single censoring karena pengamatan bisa dilakukan dengan mengunakan data yang tersedia. Penelitian ini meliputi estimasi parameter yang menggunakan Metode Bayes, yang merupakan metode estimasi berdasarkan penggabungan informasi data sampel dengan pengetahuan subyektif mengenai distribusi peluang parameter yang tidak diketahui yang disebut distribusi prior dan prior yang digunakan adalah prior inverse Gamma.

Tujuannya dari penelitian ini adalah untuk mendapatkan estimator parameter distribusi Eksponensial pada data double censoring berdasarkan distribusi prior inverse Gamma serta interval kepercayaannya.

\section{Dasar teori}

Misalkan $G(x)$ adalah fungsi dari variabel acak $x$, nilai harapan untuk $G(x)$ adalah:

$$
\begin{gathered}
E[G(x)]=\sum_{x \in \mathbb{R}} G(x) f(x) \text { jika } x \text { diskrit } \\
E[G(x)]=\int_{-\infty}^{\infty} G(x) f(x) d x \text { jika } x \text { kontinu }
\end{gathered}
$$


Misalkan $X$ dan $Y$ adalah distribusi bersama dari variabel acak maka nilai harapan bersyarat dari $Y$ dimana $X=x$ adalah :

$$
\begin{gathered}
E[Y \mid(x)]=\sum_{y} y f(y \mid x) \text { jika } X \text { dan } Y \text { diskrit } \\
E[Y \mid(x)]=\int_{-\infty}^{\infty} y f(y \mid x) d x \text { jika } X \text { dan } Y \text { kontinu }
\end{gathered}
$$

Definisi 2.1 [3] Sebuah variabel acak kontinu $X$ dikatakan memiliki distribusi Inverse Gamma dengan parameter bentuk $\alpha$ dan parameter skala $\beta$, jika fungsi kepadatan probabilitas (pdf) dari $X$ berbentuk $f(x)=\left\{\begin{array}{ccc}\frac{\beta^{\alpha}}{\Gamma(\alpha)} x^{-(\alpha-1)} e^{-\frac{\beta}{x}} & ; \text { untuk } & x>0 \\ 0 & ; \text { untuk } & \text { x lainnya }\end{array}\right.$ dan $\alpha>0 ; \beta>0$

Dalam analisis Bayesian biasanya keputusan penentuan distribusi prior memegang peranan penting. Dengan menggunakan teorema Bayes, informasi awal (prior) ini digunakan untuk mendapatkan nilai dari estimasi $\mu$, yang dinyatakan dengan fungsi likelihood yang dikombinasikan untuk membentuk distribusi posterior. Distribusi Prior dari parameter $\mu$ dilambangkan dengan $p(\mu)$ adalah fungsi probabilitas yang menyatakan tingkat kepercayaan nilai $\mu$, distribusi posterior $\infty$ likelihood $x$ distribusi prior.

Beberapa censoring dalam analisis uji hidup adalah [11]:

a. Uncensored

Dalam uji sampel lengkap ini eksperimen akan dihentikan jika semua komponen yang diuji telah mati atau gagal.

b. Left Censoring

Jika sebuah titik point berada di bawah sebuah nilai tertentu tetapi tidak diketahui berapa banyaknya.

c. Right Censoring

Jika sebuah titik point berada diatas sebuah nilai tertentu tetapi tidak diketahui berapa banyaknya [2]. 
Right Censoring terdiri dari:

i Censoring Tipe I: Dalam censoring tipe I, eksperimen akan dihentikan jika telah dicapai waktu tertentu (waktu censoring).

ii Censoring Tipe II: Suatu sampel dikatakan censoring tipe II apabila eksperimen dihentikan setelah kegagalan ke- $r$ telah diperoleh..

\section{d. Double Censoring[5]}

Dalam Double Censoring, pengamatan terhadap waktu hidup $n$ sampel acak dengan dua censoring yaitu right censoring dan left censoring, sedangkan untuk yang right censoring digunakan right censoring tipe II .Double censoring dari $n$ sample acak adalah pengamatan terhadap waktu hidup sampel ke $X_{r}, X_{r+1}, \ldots, X_{s}$, yang terurut dengan $(r-1)$ sampel terkecil serta $(n-s)$ sampel terbesar disensor.

$\overbrace{X_{1}, X_{2}, \ldots, X_{r-1}}^{\text {disensor }}, \underbrace{X_{r}, X_{r+1}, \ldots, X_{s}}_{\text {diamati }}, \overbrace{X_{s+1}, X_{s+2}, \ldots, X_{n}}^{\text {disensor }}$

Salah satu metode yang digunakan untuk mendapatkan estimator dari parameter adalah Metode Bayesian Estimation. Parameter $\mu$ dipandang sebagai variabel acak dalam ruang parameter $\mu$ dan mempunyai distribusi probabilitas $p(\mu)$ yang merupakan tingkat kepercayaan awal tentang parameter $\mu$ sebelum pengamatan dilakukan, disebut distribusi prior $\mu$. Teorema umum dari Bayes [4]

$$
p(\mu \mid y)=\frac{p(y \mid \mu) p(\mu)}{p(y)}
$$

dimana $p(\mu \mid y)$ distribusi posterior $\mu$. Distribusi bersama $p(y, \mu)$ dan distribusi marginal $p(y)$ pada umumnya tidak diketahui, biasanya hanya distribusi prior dan fungsi likelihoodnya yang dinyatakan. Rumus Bayes dapat juga ditulis [4]

$$
p(\mu \mid y) \propto l(\mu, y) p(\mu)
$$

Distribusi posterior $\infty$ likelihood $x$ distribusi prior 
Interval $\left(c_{1}, c_{2}\right)$ dari $100(1-\alpha) \%$ disebut Interval Bayesian untuk $\mu$ jika $c_{1}<c_{2}$ adalah dua konstanta, maka [7]:

$$
1-\alpha \leq P(C \mid x)= \begin{cases}\int_{C} \pi(\theta \mid x) d \theta, & \text { kontinu } \\ \sum_{\theta \in C} \pi(\theta \mid x), & \text { diskrit. }\end{cases}
$$

dengan $\pi(\theta \mid x)$ adalah distribusi posterior.

\section{Analisis dan pembahasan}

\subsection{Estimasi parameter distribusi eksponensial}

Distribusi Eksponensial secara luas digunakan sebagai suatu model lifetime yang didasarkan penelitian yang menyertakan ketahanan (survival). Jika $x$ lifetime berdistribusi Eksponensial dengan parameter $\mu$ maka pdf $f(x)$ adalah $[6]$

$$
f(x)=\frac{1}{\mu} \exp \left(-\frac{x}{\mu}\right) x>0 \quad \mu>0
$$

\subsection{Fungsi survival}

Probabilitas suatu individu oleh distribusi Eksponensial yang akan bertahan hidup sampai waktu $x$ disebut fungsi survival adalah:

$$
R(x \mid \mu)=\operatorname{Pr}(X>x \mid \mu)
$$

Sehingga dari Persamaan (1) didapatkan fungsi survival sebagai berikut:

$$
R(x \mid \mu)=\exp \left(-\frac{x}{\mu}\right)
$$

\subsection{Fungsi Likelihood}

Misalkan $x$ variabel acak berdistribusi Eksponensial dengan fungsi probabilitas $f(x, \mu)$, dan $\mu$ adalah parameter yang tidak diketahui maka pengkonstruksian fungsi likelihood dapat dinyatakan dengan 


$$
\begin{gathered}
L(x \mid \mu)=f\left(x_{1}, \mu\right) f\left(x_{2}, \mu\right) \ldots f\left(x_{n} \mu\right) \\
=\prod_{i=1}^{n} f\left(x_{i} ; \mu\right)
\end{gathered}
$$

Fungsi likelihood pada Persamaan (2) berlaku untuk tipe complete sampling, karena data pada tipe ini semua uncensored, artinya semua unit yang diuji gagal. Sedangkan untuk tipe censored sampling mempunyai fungsi likelihood yang berbeda dengan complete sampling. Ketika mengerjakan analisa maximum likelihood pada data dengan item yang belum gagal, fungsi likelihood perlu diperluas untuk menghitung item-item yang belum gagal. Secara keseluruhan teknik estimasinya tidak berubah, hanya saja pada fungsi likelihood dikenakan fungsi survivor. Fungsi likelihood untuk model survival dengan keadaan data censoring, diberikan formulasi berikut ini $[8]$ :

i Untuk uncensored: $\operatorname{Pr}(X=x \mid \mu)=f(x \mid \mu)$

Uji pada sampel lengkap ini eksperimen akan dihentikan jika semua komponen yang diuji telah mati atau gagal.

ii Untuk left censoring: $\operatorname{Pr}(X<x \mid \mu)=1-R\left(x_{r} \mid \mu\right)$

Jika sebuah titik point berada di bawah sebuah nilai tertentu tetapi tidak diketahui berapa banyaknya.

iii Untuk right censoring: $\operatorname{Pr}(X>x \mid \mu)=R\left(x_{r} \mid \mu\right)$

Jika sebuah titik point berada diatas sebuah nilai tertentu tetapi tidak diketahui berapa banyaknya.

Sample acak berukuran $n$ dari distribusi $\operatorname{Exp}(\mu)$, dimana $\mu \in U=$ $(0, \infty)$ adalah parameter yang tidak diketahui, dan menurut Fernandez (2000) misalkan $x_{r}, \ldots, x_{s}$ merupakan pengamatan terurut dari $(r-1)$ pengamatan terkecil dan $(n-s)$ pengamatan terbesar pada double censoring adalah sebagai berikut:

$\overbrace{x_{1}, x_{2}, \ldots, x_{r-1}}^{\text {disensor }}, \underbrace{x_{r}, x_{r+1}, \ldots, x_{s}}_{\text {diamati }}, \overbrace{x_{s+1}, x_{s+2}, \ldots, x_{n}}^{\text {disensor }}$ 
selanjutnya subtitusi Persamaan (2) dan (3) didapatkan fungsi likelihood untuk $\mu$ pada data double censoring adalah

$$
L(\mu \mid x)=\frac{n !}{(r-1) !(n-s) !}\left\{1-R\left(x_{r} \mid \mu\right)\right\}^{r-1}\left\{R\left(x_{r} \mid \mu\right)\right\}^{n-s} \prod_{i=r}^{s} f\left(x_{i} \mid \mu\right)
$$

sehingga diperoleh

$$
\begin{aligned}
L(\mu \mid x) & =\frac{n !}{(r-1) !(n-s) !}\left\{1-\exp \left(-\frac{x_{r}}{\mu}\right)\right\}^{r-1} \\
& \times\left\{\mu^{-(s-r+1)} \exp \left(-\frac{\sum_{i=r}^{s} x_{i}+(n-s) x_{s}}{\mu}\right)\right\}
\end{aligned}
$$

Pada Persamaan (4) dimisalkan $m=s-r+1$ dan $\xi(x)=\sum_{i=r}^{s} x_{i}+$ $(n-s) x_{s}$ sehingga

$$
L(\mu \mid x)=\frac{n !}{(r-1) !(n-s) !}\left\{1-\exp \left(-\frac{x_{r}}{\mu}\right)\right\}^{r-1}\left\{\mu^{-m} \exp \left(-\frac{\xi(x)}{\mu}\right)\right\}
$$

dengan kesebandingan didapatkan fungsi likelihood untuk $\mu$ adalah

$$
L(\mu \mid x) \infty\left\{1-\exp \left(-\frac{x_{r}}{\mu}\right)\right\}^{r-1}\left\{\mu^{-m} \exp \left(-\frac{\xi(x)}{\mu}\right)\right\}
$$

\subsection{Distribusi prior}

Menurut [5] distribusi yang tepat untuk normasi prior dari $\mu$ adalah distribusi Inverse Gamma $(a, b)$. Distribusi prior tersebut berbentuk

$$
g(\mu)=\frac{a^{b}}{\Gamma(b)} \mu^{-(b+1)} \exp \left(-\frac{a}{\mu}\right)
$$

dimana $\mu>0 a>0, b>0$. dengan kesebandingan didapatkan distribusi prior sebagai berikut:

$$
g(\mu) \infty \mu^{-(b+1)} \exp \left(-\frac{a}{\mu}\right) \text { dimana } \mu>0, a>0, b>0
$$

dengan $a$ dan $b$ diketahui. 


\subsection{Distribusi posterior}

Metode Bayesian mempunyai keuntungan dengan mengkombinasikan pengetahuan subjektif dari distribusi prior dengan pengetahuan yang ada dalam data.

Dengan mengkombinasikan fungsi likelihood dan distribusi prior didapatkan distribusi posteriornya. Persamaan umum dari distribusi posterior tersebut adalah :

$$
h(\mu \mid x)=\frac{L(\mu \mid x) p(\mu)}{\int L(\mu \mid x) p(\mu) d \mu}
$$

dengan $L(\mu \mid x)$ adalah fungsi likelihood dan $p(\mu)$ adalah distribusi prior.

Berdasarkan Persamaan (6) dan (8) nilai dari $\int L(\mu \mid x) p(\mu) d \mu$ adalah:

$$
\begin{aligned}
& \int L(\mu \mid x) p(\mu) d \mu \\
= & \int_{0}^{\infty} \mu^{-(b+1)} \exp \left(\frac{-a}{\mu}\right) \mu^{-m} \exp \left(\frac{-\xi(x)}{\mu}\right)\left(1-\exp \left(-\frac{x_{r}}{\mu}\right)\right)^{r-1} d \mu \\
= & \int_{0}^{\infty} \mu^{-(m+b+1)} \exp \left(\frac{-(a+\xi(x)}{\mu}\right)\left(1-\exp \left(-\frac{x_{r}}{\mu}\right)\right)^{r-1} d \mu
\end{aligned}
$$

dengan

$$
\begin{aligned}
\left(1-\exp \left(-\frac{x_{r}}{\mu}\right)\right)^{r-1} & =\sum_{i=0}^{r-1}\left(\begin{array}{c}
r-1 \\
i
\end{array}\right)\left(-\exp \left(-\frac{x_{r}}{\mu}\right)\right)(1)^{r-1-i} \\
& =\sum_{i=0}^{r-1}\left(\begin{array}{c}
r-1 \\
i
\end{array}\right)(-1)^{i} \exp \left(-\frac{i x_{r}}{\mu}\right)
\end{aligned}
$$


Kemudian subtitusikan Persamaan (10) ke (11), sehingga didapatkan

$$
\begin{aligned}
& \int_{0} L(\mu \mid x) p(\mu) d \mu \\
= & \int_{0}^{\infty} \mu^{-(m+b+1)} \exp \left(\frac{-(a+\xi(x)}{\mu}\right) \sum_{i=0}^{r-1}\left(\begin{array}{c}
r-1 \\
i
\end{array}\right)(-1)^{i} \exp \left(-\frac{i x_{r}}{\mu}\right) d \mu \\
= & \sum_{i=0}^{r-1}\left(\begin{array}{c}
r-1 \\
i
\end{array}\right)(-1)^{i} \int_{0}^{\infty} \mu^{-(m+b+1)} \exp \left(\frac{-\left(a+\xi(x)+i x_{r}\right.}{\mu}\right) d \mu \\
= & \sum_{i=0}^{r-1}\left(\begin{array}{c}
r-1 \\
i
\end{array}\right)(-1)^{i} \frac{\Gamma(-b+m)}{\left(a+\xi(x)+i x_{r}\right)^{(b+m)}} \\
& \int_{o}^{\infty} \frac{\left(a+\xi(x)+i x_{r}\right)^{(b+m)}}{\Gamma(b+m)} \mu^{-(m+b+1)} \exp \left(\frac{-\left(a+\xi(x)+i x_{r}\right.}{\mu}\right) d \mu
\end{aligned}
$$

maka $\int_{o}^{\infty} \frac{\left(a+\xi(x)+i x_{r}\right)^{(b+m)}}{\Gamma(b+m)} \mu^{-(m+b+1)} \exp \left(\frac{-\left(a+\xi(x)+i x_{r}\right.}{\mu}\right) d \mu=1$ sehingga Persamaan (12) akan menjadi

$$
\int L(\mu \mid x) p(\mu) d \mu=\Gamma(b+m) \sum_{i=0}^{r-1}\left(\begin{array}{c}
r-1 \\
i
\end{array}\right)(-1)^{i}\left(\partial\left(1+\frac{i x_{r}}{\partial}\right)\right)^{-(b+m)}
$$

dengan $\partial: a+\xi(x)$, diperoleh distribusi posteriornya dinyatakan sebagai berikut:

$$
h(\mu \mid x)=\frac{\mu^{-(b+1)} \exp \left(\frac{-a}{\mu}\right) \mu^{-m} \exp \left(\frac{-\xi(x)}{\mu}\right)\left(1-\exp \left(-\frac{x_{r}}{\mu}\right)\right)^{r-1} d \mu}{\Gamma(b+m) \sum_{i=0}^{r-1}\left(\begin{array}{c}
r-1 \\
i
\end{array}\right)(-1)^{-i}\left(a+\xi(x)\left(1+\frac{i x_{r}}{a+\xi(x)}\right)\right)^{-(b+m)}}
$$

Misalkan

$$
\operatorname{Fr}[a+\xi(x), b+m]=\sum_{\mathrm{i}=0}^{\mathrm{r}-1}\left(\begin{array}{c}
\mathrm{r}-1 \\
\mathrm{i}
\end{array}\right)(-1)^{-i}\left(1+\frac{i x}{a+\xi(x)}\right)^{-(b+m)}
$$

dengan $a+\xi(x), m+b>0$. Sehingga distribusi posterior pada Persamaan 
(13) dapat dinyatakan sebagai berikut:

$$
h(\mu \mid x)=\frac{\mu^{-(b+m+1)} \exp \left(\frac{-(a+\xi(x)}{\mu}\right)\left(1-\exp \left(-\frac{x_{r}}{\mu}\right)\right)^{r-1} d \mu}{\Gamma(b+m)(a+\xi(x))^{-(b+m)} \operatorname{Fr}[a+\xi(x), b+m]}
$$

\subsection{Estimator Bayes}

Dengan menggunakan fungsi kerugian kuadratik, estimator Bayes untuk $\mu(\bar{\mu})$ adalah mean dari distribusi posterior. Estimasi Bayes dapat dinyatakan sebagai berikut:

$$
\bar{\mu}=E(\mu \mid x)=\int_{0}^{\infty} \mu h(\mu \mid x) d \mu
$$

dimana $h(\mu \mid x)$ adalah distribusi posterior sesuai Persamaan (14), sehingga Persamaan (15) menjadi

$$
\begin{aligned}
\bar{\mu}= & \int_{0}^{\infty} \mu \frac{(a+\xi(x))^{(b+m)} \exp \left(\frac{-(a+\xi(x)}{\mu}\right)\left(1-\exp \left(-\frac{x_{r}}{\mu}\right)\right)^{r-1} d \mu}{\Gamma(\mathrm{b}+\mathrm{m}) \mu^{(b+m+1)} \operatorname{Fr}[a+\xi(x), b+m]} \\
= & \frac{(a+\xi(x))^{(b+m)}}{\Gamma(b+m) \operatorname{Fr}[a+\xi(x), b+m]} \\
& \int_{0}^{\infty} \mu^{-(b+m)} \exp \left(\frac{-(a+\xi(x)}{\mu}\right)\left(1-\exp \left(-\frac{x_{r}}{\mu}\right)\right)^{r-1} d \mu
\end{aligned}
$$

Persamaan $\int_{0}^{\infty} \mu^{-(b+m)} \exp \left(\frac{-(a+\xi(x)}{\mu}\right)\left(1-\exp \left(-\frac{x_{r}}{\mu}\right)\right)^{r-1} d \mu$ dapat ditulis sebagai berikut:

$$
\int_{0}^{\infty} \mu^{-(b+m)} \exp \left(\frac{-(a+\xi(x)}{\mu}\right)\left(1-\exp \left(-\frac{x_{r}}{\mu}\right)\right)^{r-1} d \mu
$$

karena

$$
\int_{0}^{\infty} \frac{\left(a+\xi(x)+i x_{r}\right)^{(b+m-1)}}{\Gamma(b+m+1)} \mu^{-((b+m-1)+1)} \exp \left(\frac{-\left(a+\xi(x)+i x_{r}\right)}{\mu}\right) d \mu=1
$$


sehingga

$$
\begin{aligned}
& \int_{0}^{\infty} \mu^{-(b+m)} \exp \left(\frac{-(a+\xi(x)}{\mu}\right)\left(1-\exp \left(-\frac{x_{r}}{\mu}\right)\right)^{r-1} d \mu \\
= & \sum_{i=0}^{r-1}\left(\begin{array}{c}
r-1 \\
i
\end{array}\right)(-1)^{i} \frac{\Gamma(b+m-1)}{\left(a+\xi(x)+i x_{r}\right)^{(b+m-1)}} \\
= & \Gamma(b+m-1)(\partial(x))^{-(b+m-1)} \sum_{i=0}^{r-1}\left(\begin{array}{c}
r-1 \\
i
\end{array}\right)(-1)^{i}\left(1+\frac{i x_{r}}{\partial}\right)^{-(b+m-1)}(17)
\end{aligned}
$$

dengan $\partial: a+\xi(x)$.

Misalkan

$\operatorname{Fr}[a+\xi(x), b+m-1]=\sum_{\mathrm{i}=0}^{\mathrm{r}-1}\left(\begin{array}{c}\mathrm{r}-1 \\ \mathrm{i}\end{array}\right)(-1)^{-i}\left(1+\frac{i x}{a+\xi(x)}\right)^{-(b+m-1)}$

dengan $a+\xi(x), m+b-1>0$

Sehingga Persamaan (17) dapat ditulis sebagai berikut:

$$
\begin{aligned}
& \int_{0}^{\infty} \mu^{-(b+m)} \exp \left(\frac{-(a+\xi(x)}{\mu}\right)\left(1-\exp \left(-\frac{x_{r}}{\mu}\right)\right)^{r-1} d \mu \\
= & \Gamma(b+m+1)(a+\xi(x))^{-(b+m-1)} \operatorname{Fr}[a+\xi(x), b+m-1]
\end{aligned}
$$

Dengan demikian estimator Bayes untuk $\mu$ pada Persamaan (16) dan substitusi dari Persamaan (18) dapat dinyatakan sebagai berikut:

$$
\bar{\mu}=\frac{\Gamma(b+m-1) \operatorname{Fr}[a+\xi(x), b+m-1]}{\Gamma(b+m) \operatorname{Fr}[a+\xi(x), b+m]}(a+\xi(x))
$$

dengan $\Gamma(b+m)=(b+m-1) \Gamma(b+m-1)$, maka estimator Bayes untuk $\mu$ adalah sebagai berikut:

$$
\bar{\mu}=\left\{\frac{F r[a+\xi(x), b+m-1]}{\operatorname{Fr}[a+\xi(x), b+m]}\right\}\left\{\frac{(a+\xi(x))}{b+m-1}\right\}
$$

dengan $m=s-r-1$ dan $\xi(x)=\sum_{i=r}^{s} x_{i}+(n-s) x_{s}$ 


\subsection{Interval kepercayaan Bayes}

Diketahui bahwa distribui posterior dari $\mu$ adalah:

$$
h(\mu \mid x)=\frac{(a+\xi(x))^{(b+m)} \exp \left(\frac{-(a+\xi(x))}{\mu}\right)\left(1-\exp \left(-\frac{x_{r}}{\mu}\right)\right)^{r-1}}{\Gamma(b+m) \mu^{(b+m+1)} F r[a+\xi(x), b+m]},
$$

dengan $\mu>0$ yaitu $100(1-\alpha) \%$ interval kepercayaan untuk $\mu$ dan $(1-\alpha)$ disebut koefisien kepercayaan

$$
1-\alpha \leq P(C \mid x)= \begin{cases}\int_{C} \pi(\theta \mid x) d \theta, & \text { kontinu } \\ \sum_{\theta \in C} \pi(\theta \mid x), & \text { diskrit. }\end{cases}
$$

dengan $\pi(\theta \mid x)$ adalah distribusi posterior.

Selanjutnya akan dicari interval kepercayaan $(1-\alpha) 100 \%$ untuk $\mu$, yaitu: $P\left(c_{1} \leq \mu \leq c_{2} \mid x\right)=1-\alpha$ dimana $\mu$ adalah parameter yang tidak diketahui dengan batas bawah memenuhi persamaan

$$
S\left(c_{1} \mid x\right)=\int_{0}^{c_{1}} h(\mu \mid x) d \mu=\frac{\alpha}{2}
$$

dan batas atas juga memenuhi persamaan

$$
S\left(c_{2} \mid x\right)=\int_{0}^{c_{2}} h(\mu \mid x) d \mu=1-\frac{\alpha}{2}
$$

Batas bawah $\left(c_{1}\right)$ dan batas atas $\left(c_{2}\right)$ ditentukan dengan menggunakan pendekatan numerik. Pendekatan integrasi numerik yang digunakan pada penelitian adalah Aturan Simpson's 1/3 berdasarkan dengan bantuan matlab 7.0.

Contoh kasus Ilustrasi permasalahan filure time (waktu kegagalan)dengan satuan menit, untuk jenis sekatan listrik type B pada suatu percobaan dimana sekatan digunakan terus menerus untuk meningkatkan tekanan voltase.

$$
\ldots, 24.4,28.6,43.2,46.9,70.7,75.3,95.5, \ldots
$$

Pada contoh ini pengamat gagal untuk mengamati dua waktu kegagalan paling kecil dan pengamatan dihentikan pada saat waktu kegagalan ke-9 
dan diketahui $a=26$ dan $b=27$. Oleh karena itu didapatkan $n=12, r=$ $3, s=9$, dan $m=7$. sehingga diproleh: $\bar{\mu}=20,47555772$ dan interval kepercayaannya

$$
15.75<\mu<28.75
$$

\section{Kesimpulan dan saran}

\subsection{Kesimpulan}

Berdasarkan hasil dan pembahasan disimpulkan sebagai berikut:

a. Estimator parameter distribusi Eksponensial pada data double censoring berdasarkan prior inverse gamma adalah:

$$
\bar{\mu}=\left\{\frac{F r[a+\xi(x), b+m-1]}{F r[a+\xi(x), b+m]}\right\}\left\{\frac{(a+\xi(x))}{b+m-1}\right\}
$$

b. Interval kepercayaan $(1-\alpha) 100 \%$ parameter distribusi Eksponensial pada data Double censoring berdasarkan distribusi prior inverse Gamma dengan $\alpha=0,05$, yaitu

$$
P\left(c_{1} \leq \mu \leq c_{2} \mid x\right)=1-\alpha .
$$

dengan batas $=0,025$ dan batas atas $=0,975$.

Nilai batas bawah $\left(c_{1}\right)$ dan batas atas $\left(c_{2}\right)$ didapatkan dengan pendekatan numerik Aturan Simpson's 1/3 dengan bantuan Matlab 7.0 . Pada penerapan contoh kasus didapatkan nilai estimasi $(\bar{\mu})=20,47555772$ dengan $\alpha=0,05$ dan didapatkan interval kepercayaan bayes dengan nilai batas bawah $\left(c_{1}\right)=15.75$ dan batas atas $\left(c_{2}\right)=28.75$ sehingga interval kepercayaannya $15.75<\mu<28.75$

\subsection{Saran}

Saran yang dapat diberikan pada pembahasan estimasi Eksponensial lifetime dengan double censoring yang menggunakan metode Estimasi Bayesian dan berdasarkan distribusi prior inverse gamma, dapat dikembangkan lebih lanjut dengan pendekatan distribusi prior yang lain misalnya : NonImformatif Prior, Conjugate Prior, Prior Proper, Prior Improper serta Reference Prior. 


\section{Pustaka}

[1] Bain, L. J. dan Max E., Introduction to Probability and Mathematical Statistics, 2nd edition, California: Duxbury Press, 1991.

[2] Berger, J.O., Statistical Decision Theory and Bayesian Analysis, 2nd ed. , Springer - Verlag, New York, 1998.

[3] Bernardo, J.M, dan Smith, A.F.M., Bayesian theory, Chichester : John Wiley \& Sons, Ltd, 2000.

[4] Box, G., dan Tiao, G. C., Bayesian Inference in Statistical Analysis, Addison-Wesley Pubhlising Company, Inc., Philippines, 1973

[5] Fernandez, J. Arturo., Estimation and Hypothesis Testing for Eksponential Lifetime Models with Double censoring and Prior Information, Journal of Economic and Social Research, 2000.

[6] Harinaldi., Prinsip-Prinsip Statistik Untuk Teknik dan Sains, Erlangga, Jakarta, 2006.

[7] Larson, H. J., Introduction to Probability Theory and Statistical Inference, John Wiley and Sons, Singapore, 1982.

[8] Miller, R. G., Survival Analysis, Wiley classics library, Stanford University, Canada, 1998.

[9] Sarwoko, Statistik Inferensi untuk Ekonomi dan Bisnis, Andi, Yogyakarta, 2007.

[10] Soehardjo, Analisis Numerik, Dosen Matematika ITS dan Institut Adhi Tama Surabaya, Surabaya, 1986.

[11] Wikipedia, the free encyclopedia., Types of Censoring, http://www.wikipedia.com., Diakses pada tanggal 23 Juni 2008. 